\title{
Anti-PD-1 Monoclonal Antibody GLS-010
}

National Cancer Institute

\section{Source}

National Cancer Institute. Anti-PD-1 Monoclonal Antibody GLS-010. NCI Thesaurus. Code C159549.

A human immunog lobulin G4 (IgG4) monoclonal antibody directed against the negative immunoregulatory human cell receptor programmed cell death protein 1 (PD-1; PDCD1; CD279), with potential immune checkpoint inhibitory and antineoplastic activities. Upon administration, anti-PD-1 monoclonal antibody GLS-010 targets, binds to and inhibits PD1 and its downstream signaling pathways. This may restore immune function through the activation of T-cells and T-cell-mediated immune responses against tumor cells. PD1, a transmembrane protein in the immunoglobulin superfamily (IgSF) expressed on Tcells, functions as an immune checkpoint that negatively regulates $\mathrm{T}$-cell activation and effector function when activated by its ligands programmed cell death-1 ligand 1 (PD-L1; B7-H1; CD274) and 2 (PD-L2); it plays an important role in tumor evasion from host immunity. 